\title{
Ovalocytosis without band 3 gene 27-bp deletion and malaria infection
}

\author{
MASAKO KIMURA $^{1}$, AUGUSTINUS SOEMANTRI ${ }^{2,3}$, JO EDI SISWANTO ${ }^{4}$, TAKAFUMI ISHIDA ${ }^{1 *}$ \\ ${ }^{1}$ Unit of Human Biology and Genetics, Department of Biological Sciences, Graduate School of Science, The University of Tokyo, \\ 7-3-1 Hongo, Bunkyo-ku, Tokyo, 113-0033 Japan \\ ${ }^{2}$ Department of Child Health, Faculty of Medicine, Diponegoro University, Semarang, Indonesia \\ ${ }^{3}$ Dr. Kariadi Hospital, Semarang, Indonesia \\ ${ }^{4}$ Health Center, Waingapu, Nusa Tenggara Timur/RS Ibu dan Anak Harapan Kita-Jakarta, Indonesia
}

Received 2 August 2005; accepted 7 December 2005

\begin{abstract}
Genetic adaptation to malaria is a longstanding research topic in anthropology and human genetics. Southeast Asian ovalocytosis (SAO) has been documented to have resistance to malaria; however, the implications of existing data are controversial. In particular, SAO resistance to malaria is unlcear in terms of the types of SAO, with/without the 27-base pair deletion in the band 3 gene (B3 $\Delta 27)$. To shed light on the relationships between SAO and malaria, we surveyed Plasmodium infection, erythrocyte morphology, and the presence of the B3 $\Delta 27$ among the residents of a selected area in East Kalimantan, Indonesia where malaria is endemic. We screened peripheral blood smears $(n=128)$ for Plasmodium infection and erythrocyte morphology under a microscope, and then DNA was extracted from the smears to be used as a template for a polymerase chain reaction to detect the B3 $\Delta 27$. The prevalence of infection with Plasmodium including Plasmodium vivax and Plasmodium falciparum was approximately $30 \%$. Among a total of 128 subjects, $9.4 \%$ and $18.0 \%$ showed moderate (ovalocytic cells: 30-49\%) and severe (ovalocytic cells: 50-100\%) ovalocytosis, respectively. A total of three B3 $\Delta 27$ carriers were identified. The data set was statistically analyzed and we observed that (1) higher ovalocytic rate resulted in lower malaria infection and (2) the B3 $\Delta 27$ did not prevent malaria infection. These results suggest that resistance of SAO to malaria is due to SAO without the B3 $\Delta 27$.
\end{abstract}

Key words: Southeast Asian ovalocytosis (SAO), band 3 (AE1) gene, Indonesia, malaria

\section{Introduction}

Genetic adaptation to malaria is a longstanding research topic in anthropology and human genetics. Certain red blood cell (RBC) defects are suggested to have resistance to malaria. RBC defects, including those with altered RBC shape, have been reported from several malaria-endemic regions. The distribution of the defects meets the hypothesis that subsets of the RBC defects became prevalent through natural selection by malaria. The most famous example of such malaria-resistant RBC defects is sickle cell anemia.

$\mathrm{RBC}$ deformity is another example of such RBC defects in the Asian-Pacific region where ovalocytosis has commonly been recorded. Among several types of hereditary ovalocytosis recorded to date, Southeast Asian ovalocytosis (SAO) is characterized by the oval shape of red blood cells and is clinically asymptomatic. This type of hereditary ovalocytosis has been observed widely in Southeast Asia and Melanesia and the prevalence is as high as $50 \%$ in some populations (Lie-injo, 1965; Amato and Booth, 1977). Serjeantson et al. (1977) hypothesized that SAO is resistant to malaria because the distribution of SAO coincides with

* Corresponding author. e-mail: tishida@biol.s.u-tokyo.ac.jp phone: +81-3-5841-4633; fax: +81-3-3818-7547

Published online 8 March 2006

in J-STAGE (www.jstage.jst.go.jp) DOI: 10.1537/ase.050802 malaria endemic areas. The higher frequencies of SAO found in adults than in the young of the same population in malaria endemic areas (Baer et al., 1976) also supported this hypothesis and suggested a selective advantage of SAO in such areas. However, several studies on malaria resistance of SAO are controversial in terms of parasite density or Plasmodium species (Baer et al., 1976; Serjeantson et al., 1977; Cattani et al., 1987; Foo et al., 1992).

A 27-bp deletion in the band 3 gene [Band3, EPB3, AE1: solute carrier family 4 member 1 (SLC4A1), OMIM+1092700002] found among individuals with SAO (Jarolim et al., 1991) was considered the underlying molecular basis for SAO; however, the 27-bp deletion in the band 3 gene (B3 $\Delta 27$ ) did not account for all SAO cases (Tanner et al., 1991). Moreover, low frequencies of the B3 $\Delta 27$ in Southeast Asians were demonstrated (Kimura et al., 1998) and the presence of other molecular mechanism(s) for SAO is thus postulated. The diagnosis of SAO used to be based on erythrocyte morphology with poorly standardized criteria; relationships between Plasmodium infection and SAO have been promiscuous probably due to these unsystematic criteria. After the discovery of the $\mathrm{B} 3 \Delta 27$, relationships between SAO caused by the $\mathrm{B} 3 \Delta 27$ (B3 $\Delta 27-\mathrm{SAO})$ and malaria resistance were studied and severity of malarial disease symptoms was shown to subside in individuals with B3 $\Delta 27-\mathrm{SAO}$ (Allen et al., 1999). However, the resistance of SAO to malaria disease is still unclear in terms of the types of SAO, 
with/without the B3 $\Delta 27$, as well as Plasmodium species. Our previous study showed that the B3 $\Delta 27$ did not alter the parasite infection rate or the species-specific prevalence (Kimura et al., 2002; Shimizu et al., 2005).

To shed light on relationships between ovalocytosis and malaria, we have screened for malaria infection, erythrocyte morphology, and the B3 $\Delta 27$ in East Kalimantan, Indonesia.

\section{Materials and Methods}

A survey was carried out in Tanjung Redep, East Kalimantan, Indonesia (Figure 1), where malaria was endemic. The residents were of mixed population with different ethnic origins. Among them, Berau was the major and indigenous tribe in the region followed by other tribal groups such as Manado, Toraja, and Bugis who had migrated from northern, central, and southern Sulawesi Island, respectively. A total of 128 individuals (age range: 1-63 years; mean age: 28 years) (Table 1) were recruited and blood specimens were collected with oral informed consent.

Thick and thin blood smears were prepared and stained with Giemsa for microscopic examination. The presence of malaria parasites and the frequency of ovalocytic cells were determined by an experienced hematologist. According to the frequency of ovalocytic cells observed on the blood smears, subjects were categorized into three groups (fre-

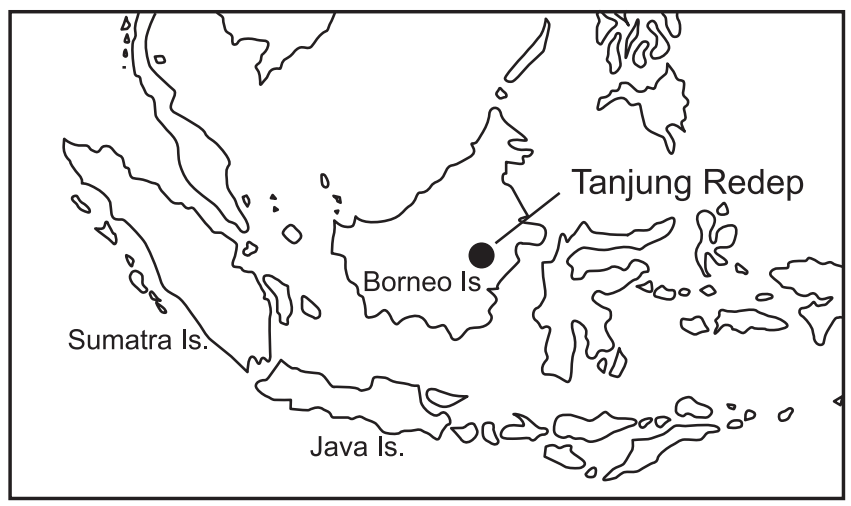

Figure 1. Location of the survey area.

Table 1. Ovalocytosis and malaria infection in each group in Tanjung Redep, East Kalimantan, Indonesia

\begin{tabular}{|c|c|c|c|c|c|c|c|}
\hline \multirow[b]{2}{*}{ Group } & \multirow[b]{2}{*}{$n$} & \multicolumn{3}{|c|}{ Group of ovalocytosis } & \multicolumn{3}{|c|}{ Plasmodium $^{1}$} \\
\hline & & $\mathrm{L}$ & $\mathrm{M}$ & $\mathrm{H}$ & $v$ & $f$. & $v$. and $f$. \\
\hline Berau & 79 & 53 & 10 & $16^{3}$ & 11 & 5 & 6 \\
\hline Bugis & 21 & 18 & 0 & 3 & 5 & 1 & 1 \\
\hline Manado & 9 & 6 & $2^{4}$ & 1 & 0 & 0 & 0 \\
\hline Toraja & 9 & 7 & 0 & 2 & 3 & 2 & 0 \\
\hline Others $^{2}$ & 10 & 9 & 0 & 1 & 2 & 2 & 0 \\
\hline Total & 128 & 93 & 12 & 23 & 21 & 10 & 7 \\
\hline \multicolumn{8}{|c|}{$\begin{array}{l}1 \text { v.: vivax; } f: \text { falciparum. } \\
2 \text { Others: Javanese }(n=4) \text {, Batak }(n=2) \text {, Dayak }(n=2) \text { and Timor } \\
\text { thnic groups }(n=2) .\end{array}$} \\
\hline
\end{tabular}

quency of ovalocytic cells): group L (0-29\%), group M (30$49 \%$ ), and group H (50-100\%) (Cattani et al., 1987; Mgone et al., 1998). Genomic DNA was extracted from blood films with the standard phenol/chloroform method. The B3 $\Delta 27$ was studied by a polymerase chain reaction (PCR) method with a specific primer set (5'-GGGCCCAGATGACCCTCTTGC-3' and 5'-GCCGAAGGTGATGGCGGGTG$\left.3^{\prime}\right)$ spanning the 27-bp deletion (Jarolim et al., 1991). An initial denaturation at $95^{\circ} \mathrm{C}$ for 9 minutes was followed by 40 cycles of denaturation at $94^{\circ} \mathrm{C}$ for 1 minute and annealing and extension at $70^{\circ} \mathrm{C}$ for 1 minute with a final extension at $70^{\circ} \mathrm{C}$ for 5 minutes. The wild type and the deletion type allele was identified by the size of the PCR product corresponding to $175 \mathrm{bp}$ and $148 \mathrm{bp}$, respectively. PCR for glycophorin C (GPC) exon 3 was carried out as described by Patel et al. (2001) for those ovalocytosis without the B $3 \Delta 27$. The PCR products were subjected to electrophoresis on $4 \%$ agarose gel and visualized with ethidium bromide.

\section{Results and Discussion}

Of a total of 128 blood smears, $72.6 \%, 9.4 \%$, and $18.0 \%$ was categorized into groups $\mathrm{L}, \mathrm{M}$, and $\mathrm{H}$, respectively (Table 1). The B3 $\Delta 27$ was found only in three subjects $(2.3 \%)$ who belonged to the Berau $(n=2$; group $\mathrm{H})$ and the Manado ( $n=1$; group M). This low frequency of the B3 $\Delta 27$ is consistent with the previous report (Kimura et al., 1998), and highlights the high prevalence of ovalocytosis that is not caused by the $\mathrm{B} 3 \Delta 27$.

The prevalence of infection with Plasmodium vivax $(P$. vivax), $P$. falciparum and both species was $7.8 \%, 16.4 \%$, and $5.5 \%$, respectively. The frequency of ovalocytic cells and malaria infection was negatively correlated (CochranArmitage's trend test, $P=0.0046$ ) (Figure 2). The prevalence of malaria infection in group $\mathrm{H}$ was significantly lower when compared with the rest of the population (namely groups L and M) (Fisher's exact test, $P=0.0038$ ); this result was significant irrespective of inclusion or exclusion of the B $3 \Delta 27$ cases $(n=3)$. As for the parasite species, resistance to both $P$. falciparum. and $P$. vivax was demonstrated; however, resistance to $P$. vivax was more obvious. In an attempt to minimize confounding effects by heterogeneous genetic backgrounds, only the Berau ethnic group $(n=79)$ was then subjected to the previous analysis, and a negative correlation was also observed (Cochran-Armitage's trend test, $P=0.007$ ).

We have observed the following two relationships between ovalocytosis and malaria in this study: 1) higher ovalocytic rate results in lower malaria infection, and 2) ovalocytosis without $\mathrm{B} 3 \Delta 27$ may have protective effects against malaria. These observations may necessitate a reevaluation of the hypothetical implications of SAO to malaria resistance. There have been several controversial reports on the resistance of SAO against malaria. Recent studies on the relationships between malaria and the B3 $\Delta 27$ revealed that $\mathrm{B} 3 \Delta 27-\mathrm{SAO}$ provides protection against cerebral malaria but does not affect infection rate and density of either P. falciparum or P. vivax (Genton et al., 1995; Allen et al., 1999; Kimura et al., 2002; Shimizu et al., 2005). Morphologically identified SAO was thought to have preventive 


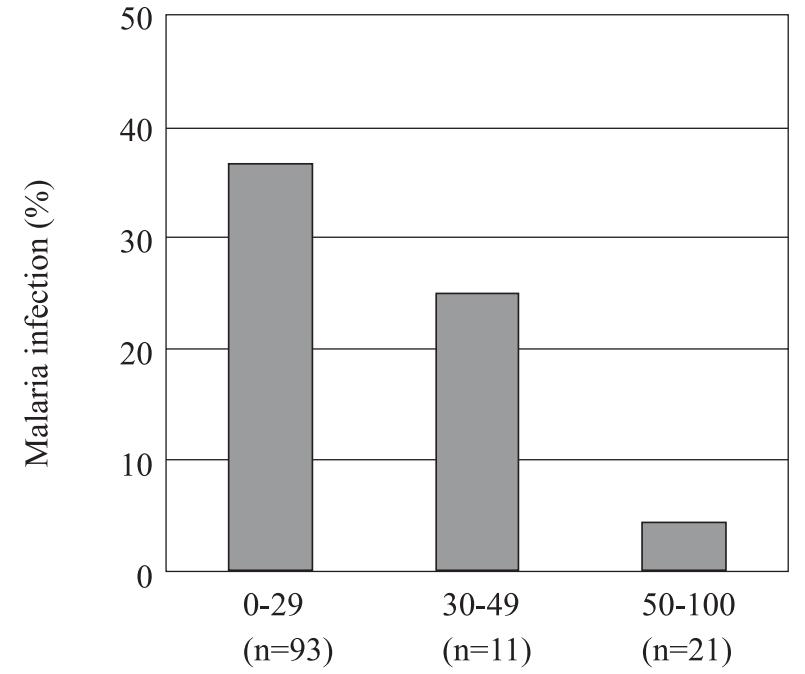

Ovalocytic cells (\%)

Figure 2. Frequency of ovalocytic cells and malaria infection. Groups $\mathrm{L}, \mathrm{M}$, and $\mathrm{H}$ in the text correspond to $0-29 \%, 30-49 \%$, and $50-100 \%$ ovalocytes, respectively.

features such as resistance to high density of parasitemia, and decreased rates of infection by $P$. vivax, $P$. malariae, and $P$. falciparum (Baer, 1976; Serjeantson, 1977; Cattani et al., 1987; Foo et al., 1992); however, this category of SAO comprised B3 $\Delta 27-\mathrm{SAO}$ and other type(s) of SAO. Because the B3 $\Delta 27$ did not lead to resistance to Plasmodium infection, it is conceivable that the reduced Plasmodium infection observed in the previous microscopic studies was due to $\mathrm{SAO}$ without the $\mathrm{B} 3 \Delta 27$.

Mgone et al. (1998) indicated that microscopic diagnosis of ovalocytosis can be influenced by the inter- and intravariation on the part of the observer. As the B3 $\Delta 27-\mathrm{SAO}$ displays a wide range of ovalocytic phenotype, the results of past reports should be reconsidered on the presumption that microscopically diagnosed SAO comprises several molecular bases. In fact, the presence of two distinctive types of SAO, with and without the B3 $\triangle 27$ (Cattani et al., 1987; Tanner et al., 1991), has been reported in Papua New Guinea. One of the molecular bases for such SAO without the B3 427 in Papua New Guinea was recently revealed as a deletion of GPC exon 3; the frequency and intensity of bloodstage $P$. falciparum or $P$. vivax infection was not associated with the GPC genotype (Patel et al., 2001). Concerning the ovalocytosis observed in the eastern part of Borneo Island in this study, the presence of the reported deletion in the GPC gene was not confirmed by PCR, which suggests the presence of other molecular mechanism(s) for this SAO with protective effect on malaria infection.

The controversial implications of the malaria resistance of SAO in earlier studies can be attributed to the admixture of molecularly heterogeneous SAO. In the present study, SAO without the B $3 \Delta 27$ is clearly shown to contribute to lowering malaria infection rates. As it is fully expected that SAO identified microscopically cannot be attributed to a single molecular basis as shown in the previous and present stud- ies, the existence of malaria-resistant SAO without the $\mathrm{B} 3 \Delta 27$ awaits the identification of the underlying molecular bases.

\section{Acknowledgments}

This work was partly supported by the grants from the Ministry of Education, Culture, Sports, Science and Technology, Japan and Japan Society for the Promotion of Science. This study constitutes a part of the doctoral dissertation of M.K. submitted to The University of Tokyo.

\section{References}

Allen S.J., O'Donnell A., Alexander N.D., Mgone C.S., Peto T.E.A., Clegg J.B., Alpers M.P., and Weatherall D.J. (1999) Prevention of cerebral malaria in children in Papua New Guinea by Southeast Asian ovalocytosis band 3. American Journal of Tropical Medicine and Hygiene, 60: 1056-1060.

Amato D. and Booth P.B. (1977) Hereditary ovalocytosis in Melanesians. Papua New Guinea Medical Journal, 20: 26-32.

Baer A., Lie-Injo L.E., Welch Q.B., and Lewis A.N. (1976) Genetic factors and malaria in the Temuans. American Journal of Human Genetics, 28: 179-188.

Cattani J.A., Gibson F.D., Alpers M.P., and Crane G.G. (1987) Hereditary ovalocytosis and reduced susceptibility to malaria in Papua New Guinea. Transactions of the Royal Society of Tropical Medicine and Hygiene, 81: 705-709.

Foo L.C., Rekhraj V., Chiang G.L., and Mak J.W. (1992) Ovalocytosis protects against severe malaria parasitemia in the Malayan Aborigines. American Journal of Tropical Medicine and Hygiene, 47: 271-275.

Genton B., Al-Yaman F., Mgone C.S., Alexander N., Paniu M.M., and Alpers M.P. (1995) Ovalocytosis and malaria. Nature, 378: 564-565

Jarolim P., Palek J., Amato D., Hassan K., Sapak P., Nurse G.T., Rubin H.L., Zhai S., Sahr K., and Liu S.C. (1991) Deletion in erythrocyte band 3 gene in malaria-resistant Southeast Asian ovalocytosis. Proceedings of the National Academy of Sciences of the United States of America, 88: 11022-11026.

Kimura M., Shimizu Y., Settheetham-Ishida W., Soemantri A., Tiwawech D., Romphruk A., Duanchang P., and Ishida T. (1998) Twenty-seven base pair deletion in erythrocyte band 3 protein gene responsible for Southeast Asian ovalocytosis is not common among Southeast Asians. Human Biology, 70: 993-1000.

Kimura M., Soemantri Ag., and Ishida T. (2002) Malaria species and Southeast Asian ovalocytosis defined by a 27-bp deletion in the erythrocyte band 3 gene. Southeast Asian Journal of Tropical Medicine and Public Health, 33: 4-6.

Lie-Injo L.E. (1965) Hereditary ovalocytosis and haemoglobin Eovalocytosis in Malayan Aborigines. Nature, 208: 1329.

Mgone C.S., Genton B., Peter W., Paniu M.M., and Alper M.P. (1998) The correlation between microscopic examination and erythrocyte band 3 (AE1) gene deletion in south-east Asian ovalocytosis. Transactions of the Royal Society of Tropical Medicine and Hygiene, 92: 296-299.

Patel S.S., Mehlotra R.K., Kastens W., Mgone C.S., Kazura J.W., and Zimmerman P.A. (2001) The association of the glycophorin $\mathrm{C}$ exon 3 deletion with ovalocytosis and malaria susceptibility in the Wosera, Papua New Guinea. Blood, 98: 3489-3491.

Serjeantson S., Bryson K., Amato D., and Babona D. (1977) Malaria and hereditary ovalocytosis. Human Genetics, 37: 161-167.

Shimizu H., Tamam M., Soemantri A., and Ishida T. (2005) Glucose-6-phosphate dehydrogenase deficiency and Southeast 
Asian ovalocytosis in asymptomatic Plasmodium carriers in Sumba island, Indonesia. Journal of Human Genetics, 50: 420-424.
Tanner M.J.A., Bruce L., Martin P.G., Reardon D.M., and Jones G.L. (1991) Melanesian hereditary ovalocytes have a deletion in red cell band 3. Blood, 78: 2785-2787. 